\title{
APLICACIÓN DE LOS POSTULADOS DE AMNISTÍA E INDULTO EN LA JURISPRUDENCIA EMITIDA POR LA JEP PARA LOS EXGUERRILLEROS EN COLOMBIA EN EL PERIODO COMPRENDIDO ENTRE 2017-2020
}

Lina María Hernández Garavito*, Valentina Ardila García**

\section{Resumen}

La presente investigación pretende realizar un análisis en lo concerniente a los postulados de amnistía e indulto estipulados en el ordenamiento legal, jurisprudencial y doctrinal colombiano, ubicándolo en el panorama que se creó a partir de los acuerdos de paz entre el Gobierno Nacional y las FARC-EP en el 2016, y posterior a ello verificar la aplicación de los mismos analizando la jurisprudencia emitida por la Jurisdicción Especial para la Paz. Se trató de una investigación cualitativa con un enfoque histórico hermenéutico, cuya población son las sentencias emitidas por la Sala de Amnistía e Indulto; lo anterior, se analizó por medio de fichas de análisis jurisprudencial y de listas de chequeo. Finalmente, se logró contribuir con la apreciación inicial y dar respuesta a la pregunta problema utilizando los métodos de investigación y analizando la jurisprudencia emitida por la JEP frente a los postulados de amnistía e indulto. 


\section{Introducción}

La presente investigación está enfocada en la jurisprudencia emitida por la Jurisdicción Especial para la Paz (JEP) en materia de amnistía o indulto que se encuentra regulada en Colombia por la Ley 1820 del 2016 (Ley de amnistía, indulto y otros tratamientos penales especiales); y nació después de la firma del acuerdo final de paz celebrado entre el Gobierno Nacional, que en ese entonces se encontraba bajo el mandato de Juan Manuel Santos, y el grupo armado al margen de la ley FARC-EP. Asimismo, la investigación se centra determinar si se le ha otorgado la debida aplicación a la JEP con base en los postulados en materia legal, jurisprudencial y doctrinal en Colombia.

La Ley 1820 del 2016, en su artículo 2, tiene como objeto la regulación de lo concerniente a las amnistías e indultos por los delitos políticos y los delitos conexos para excombatientes guerrilleros que cumplan con las siguientes condiciones: i) hayan firmado un acuerdo de paz con el Gobierno Nacional, ii) que hayan dejado las armas. Así como adoptar tratamientos penales especiales diferenciados para agentes del Estado y terceros civiles.

La misma ley en su artículo 42, define la amnistía como un mecanismo que extingue la acción penal, disciplinaria, administrativa y fiscal por conductas que se relacionan con el conflicto armado. La amnistía se concede con el fin de lograr la terminación en una extensión definitiva del conflicto armado en Colombia y la satisfacción de las víctimas en cuanto a los postulados de verdad, justicia, reparación y garantía de no repetición.
En el ordenamiento jurídico colombiano, quienes están en la facultad de conceder amnistías e indultos son:

- El presidente de la República por mandato constitucional (Const. Pol., art. 201, num. 2) puede otorgar indultos: Conceder indultos por delitos políticos, con arreglo a la ley, e informar al Congreso sobre el ejercicio de esta facultad. En ningún caso estos indultos podrán comprender la responsabilidad que tengan los favorecidos respecto de los particulares.

- El Congreso de la República mediante mandato constitucional (Const. Pol., art. 150, num. 17) puede dentro de sus funciones otorgar la concesión de amnistías de la siguiente forma: Conceder, por mayoría de los dos tercios de los votos de los miembros de una y otra Cámara y por graves motivos de conveniencia pública, amnistías o indultos generales por delitos políticos. En caso de que los favorecidos fueren eximidos de la responsabilidad civil respecto de particulares, el Estado quedará obligado a las indemnizaciones a que hubiere lugar.

- La Sala de Amnistía e Indulto de la Jurisdicción Especial para la Paz, mediante el poder que le confiere la ley después de la firma final de los acuerdos de paz del 2016, puede conceder amnistías $\mathrm{o}$ indultos por medio de decisiones judiciales a aquellos excombatientes que cumplan con unos requisitos previos, que serán mencionados posteriormente.

La investigación asociada a la jurisprudencia emitida por la JEP, se realizó bajo el interés de conocer los límites acogidos por la JEP a la hora de conceder amnistías a quienes las soliciten, con el fin de saber 
los motivos por los que a una persona que durante su vinculación al grupo armado cometió múltiples delitos tipificados en la legislación penal colombiana, por qué se le confieren amnistías a excombatientes, y saber si la misma aplica para particulares. A raíz de los interrogantes aquí expuestos, surge el interrogante y a partir de ello el interés de entender en qué se basa la JEP al momento de la concesión de las variables aquí expuestas.

Resulta pertinente destacar entonces, que todo aquello que concierne al tema de la concesión de amnistías por parte de la Sala de Amnistía e Indulto de la JEP, debe hacerse según los lineamientos legales de derecho interno y este, a su vez, regirse por los mandatos de Derecho Internacional Humanitario.

\section{Materiales}

La creación del presente artículo lleva consigo una población determinada, como lo es la jurisprudencia emitida por la Sala de Amnistía e Indulto de la JEP y cuya muestra seleccionada son cuatro de los fallos judiciales emitidos por la JEP en materia de amnistía e indulto. Estos permiten que por medio del análisis individual se llegue a la determinación del procedimiento y postulados que se tuvieron en cuenta para llegar a la decisión que se le profiera a cada una, razón por la cual se eligieron fallos que conceden la amnistía y otros que no la conceden.

-Sentencia 20181510136082; cuyo peticionario es el señor Félix Ortiz Amaya. -Sentencia 20181510121692; cuyo peticionario es el señor Jorge Iván Sandoval Aguirre.
-Sentencia 20181510370722; cuyo peticionario es el señor Jhon Elvis Sotar Camelo.

-Sentencia 20181510069482; cuyo peticionario es el señor Yonatan Carvajal Castiblanco.

Se utilizaron instrumentos como las fichas de análisis jurisprudencial y listas de chequeo que permiten la verificación de los postulados de amnistía e indulto y, gracias a ello, concluir si definitivamente se está cumpliendo con los mismos o si, por el contrario, los están omitiendo a la hora de dictar sentencias.

\section{Métodos}

El tipo de investigación que se utilizó fue de tipo cualitativo, con un enfoque de tipo histórico hermenéutico, ya que trató en primera medida de entender la realidad de la situación en virtud del tema principal del proyecto; por consiguiente, fue necesario conocer el proceso histórico por el cual ha tenido que pasar el país en relación con el conflicto armado que vivieron sus habitantes por parte de las FARC y las múltiples violaciones a sus derechos como personas.

El diseño utilizado es de tipo documental, pues para lograr llevar a cabo los objetivos de la misma se hizo necesario estudiar, revisar y analizar lo referente a la normatividad, la jurisprudencia y la doctrina basadas en el tema específico de la amnistía y el indulto. Se trata, entonces, de una investigación que requirió de estudio de documentos previos sobre los temas centrales que motivaron el presente proyecto para, asimismo, dar una posterior respuesta basada en 
el análisis de fallos judiciales proferidos por la Jurisdicción Especial para la Paz en el marco del conflicto armado que se vivió en el país y, específicamente, en el tema central de la amnistía e indulto.

\section{Resultados}

La presente investigación tiene como cometido, determinar por medio del análisis de la jurisprudencia emitida por la JEP, si a la hora de aplicar la concesión o no de amnistías o indultos, lo realizan bajo los lineamientos estipulados por la legislación, la doctrina y la jurisprudencia colombiana. Por ello, luego del estudio de las sentencias anteriormente mencionadas, se logra determinar el momento de analizar los fallos emitidos por la Sala de Amnistía e Indulto. La JEP es cuidadosa con el tema de la concesión de amnistías, pues realiza análisis previos de carácter objetivo, según lo dispuesto en la normatividad colombiana que, a su vez, se acoge a los lineamientos de carácter internacional (Estatuto de Roma, Protocolo Adicional II a los convenios de Ginebra).

Después de realizar el estudio legislativo, jurisprudencial y doctrinal en Colombia, en lo que concierne a la materia de la amnistía y el indulto, se logra determinar que jurisprudencialmente y en términos legales, si existe una definición y regulación específica para el tema, no es antigua; por el contrario, la legislación aplicada al tema radica en la última década y de igual forma sucede con las sentencias, producidas a partir del 2016 con la entrada en vigencia del Acuerdo de Paz firmado entre el Gobierno Nacional y las FARC-EP. El es- tudio de la figura jurídica denota el beneficio del perdón de la pena a aquellos excombatientes que cumplan con los requisitos estipulados por la ley. Esto es claro en materia jurisprudencial y legal. Sin embargo, desde la perspectiva de la doctrina, no son muchos los autores en Colombia que hasta el momento han realizado investigaciones de este tipo.

Por otro lado, el segundo objetivo se centró en analizar los fallos emitidos por la JEP en materia de amnistía o indulto, y mediante el estudio de las sentencias seleccionadas y los instrumentos utilizados, poder llegar a la determinación de que al momento de hacer el control previo al fallo, la Sala de Amnistía e Indulto se ciñe a la reglamentación legal del Estado colombiano, cumpliendo así con el análisis de la Ley 1820 de 2016 y las demás que fundan y forman parte de la concesión de amnistías e indultos. En caso de alguna existencia de vacíos, se basan en el precedente originado con base en la jurisprudencia aplicada al tema. Lo anterior, teniendo en cuenta los aspectos de carácter temporal, material y personal del peticionario que busca se le conceda el beneficio de la amnistía.

\section{Discusión}

Si bien es cierto, la amnistía y el indulto son una figura jurídica novedosa en el marco jurídico colombiano, la cual tuvo gran relevancia a partir de la entrada en vigencia del Acuerdo Final de Paz. Tal figura fue implementada en la Justicia Especial para la Paz, siendo un mecanismo esencial para así avanzar en la reconciliación, darles fin a las hostilidades y, de tal manera, generar confianza y equidad 
entre las partes. Consecuente con lo anterior, siendo esta un papel fundamental en la paz, para su aplicación se establecieron ciertas limitaciones debido a su nivel jerárquico superior y con el fin de darle protección a las víctimas inmersas en el contexto del conflicto armado, tales como las violaciones al Derecho Internacional Humanitario (DIH), los crímenes de guerra, los crímenes de lesa humanidad.

Conforme a lo descrito en la presente investigación, las amnistías otorgadas por la JEP en las sentencias judiciales han sido verídicas y radicales en la aplicación de la figura jurídica, ya que han sido estrictas en su concesión y han dado aplicación a las limitaciones que define el marco jurídico interno e internacional. Ha obedecido rigurosamente los pronunciamientos de la Corte Constitucional y, además, de su situación controversial, la cual ha sido bastante polarizada por el impacto en la sociedad. Tales sentencias han tenido una acogida calurosa por parte de los doctrinantes, teniendo estos conceptos favorables y siguiendo la línea ideológica y jurídica de la Ley de Amnistía e Indulto (Ley 1820 de 2016).

\section{Sugerencias}

Se logra llegar a la determinación de que al analizar y evaluar si el peticionario es beneficiario o no de la amnistía, la Sala de Amnistía e Indulto de la JEP hace un análisis juicioso con base en los postulados existentes en el marco normativo colombiano, ciñéndose a la Ley 1820 de 2016 (Ley de Amnistía e Indulto y otros tratamientos penales especiales), valiéndose de tres componentes que forman un núcleo a la hora de tomar cualquier decisión. Si la persona cumple con ellos, gozará del beneficio de la amnistía, si la persona no cumple con los requisitos previos su petición será negada.

\section{Agradecimientos}

Como autores de la presente investigación, ofrecemos infinitos agradecimientos a la Fundación Universitaria del Área Andina por proporcionarnos la oportunidad de participar en la creación del presente, y a la docente asesora Jenny Chalarca, quien nos orientó en el proceso de creación y estructuración del contenido a apreciar.

\section{Referencias}

1. Chaparro, N. (2013). Laamnistía eindulto en Colombia 1965-2012 (trabajo de maestría). Universidad Nacional de Colombia. https://repositorio.unal.edu.co/bitstream/ handle/unal/75350/1052380923.2013. pdf? sequence $=1$ \&isAllowed=y Congreso de Colombia. (30 de diciembre del 2016). Ley de amnistía, indulto y tratamientos penales especiales. [Ley 1820 de 2016]. Diario Oficial No. 50.102.

2. Constitución Política de Colombia. (1991). Artículo 150 (título Iv); artículo 201 (título VII). $2^{a}$ edición. http://www.secretariasenado.gov.co/senado/basedoc/constitucion_politica_1991_pr006.html

3. Corte Constitucional de Colombia, Sala Plena. (28 de agosto del 2002). Sentencia C-695/2002. [M. P., Jaime Córdoba Triviño].

4. Corte Constitucional de Colombia, Sala Plena. (11 de abril del 2018). Sentencia C-025/2018. [M. P., José Fernando Reyes].

5. Corte Constitucional de Colombia, Sala Plena. (28 de agosto del 2013). Sentencia C-579/2013. [M. P., Jorge Ignacio Pretal]. 
6. Corte Constitucional de Colombia, Sala Plena. (1 de marzo del 2018). Sentencia C-007/2018. [M. P., Diana Fajardo Rivera].

7. Jurisdicción Especial para la Paz, Sala de Amnistía e Indulto. (16 de diciembre del 2019). Sentencia SAI-AI-DRJC-0196-2019. [M. P., Reinere de los Ángeles Jaramillo Chaverra].

8. Jurisdicción Especial para la Paz, Sala de Amnistía e Indulto. (22 de marzo del 2019). Sentencia SAI-Al-LRG-012-2019. [M. P., Lily Andrea Rueda Guzmán].

9. Observatorio de Paz y Conflicto. (2016). Amnistía e indulto. Universidad Nacional de Colombia. http://www.humanas.unal.edu.co/observapazyconflicto/ files/1114/6558/5997/OPC_amnistia_indulto_snt.pdf

10. Sistema integral de verdad, justicia, reparación y no repetición (SIVJRNR). (2019). Jurisdicción Especial para la Paz. https://www.jep.gov.co/Infografas/ SIVJRNR_ES.pdf
11. Presidencia de la República de Colombia. (17 de febrero del 2017). "Por el cual se establece el procedimiento para la efectiva implementación de la Ley 1820 del 30 de diciembre de 2016". [Decreto 227 de 2017]. http://es.presidencia.gov. co/normativa/normativa/DECRETO $\% 20$ $277 \% 20$ DEL $\% 2017 \% 20$ FEBRERO $\% 20$ DE\%202017.pdf

12. Presidencia de la República de Colombia. (21 de noviembre del 2016). Acuerdo final para la terminación del conflicto y la construcción de una paz estable y duradera. https://www.jep.gov.co/Marco\%20 Normativo/Normativa_v2/01\%20ACUERDOS/N01.pdf

13. Redacción W Radio. (16 de enero del 2020). JEP tomó 16.500 decisiones en 82 audiencias durante 2019. https:// www.wradio.com.co/noticias/actualidad/ jep-tomo-16500-decisiones-en-82-audiencias-durante-2019/20200116/ nota/4003408.aspx 